\title{
Inhibition of Miro1 disturbs mitophagy and pancreatic $\beta$-cell function interfering insulin release via IRS-Akt-Foxo1 in diabetes
}

\author{
Lingling Chen ${ }^{1,2, *}$, Chunyan Liu ${ }^{1, *}$, Jianfeng Gao ${ }^{1}$, Zhiwen $\mathrm{Xie}^{3}$, Lawrence W.C. \\ Chan $^{4}$, Damien J. Keating ${ }^{5}$, Yibin Yang ${ }^{6}$, Jiazhong Sun ${ }^{7}$, Fuling Zhou ${ }^{8}$, Yongchang \\ Wei $^{9}$, Xiuli Men ${ }^{10}$ and Sijun Yang ${ }^{1}$ \\ ${ }^{1}$ ABSL-3 Laboratory at the Center for Animal Experiment and Institute of Animal Model for Human Disease, Wuhan University \\ School of Medicine, Wuhan, P. R. China \\ 2 Department of Cell Biology, College of Life Science, Nanjing Normal University, Nanjing, Jiangsu, P.R. China \\ ${ }^{3}$ School of Bioscience and Technology, Weifang Medical University, Weifang Shandong, P.R. China \\ ${ }^{4}$ Department of Health Technology and Informatics, Hong Kong Polytechnic University, Hong Kong, Hong Kong \\ ${ }^{5}$ Department of Human Physiology and Centre for Neuroscience, Flinders University, Adelaide, South Australia, Australia \\ ${ }^{6}$ Department of Endocrinology, Zhongnan Hospital of Wuhan University, Wuhan, Hubei, P.R. China \\ 7 Department of Respiratory, Zhongnan Hospital of Wuhan University, Wuhan, Hubei, P.R. China \\ ${ }^{8}$ Department of Hematology and Radiation, Zhongnan Hospital of Wuhan University, Wuhan, Hubei, P.R. China \\ ${ }^{9}$ Department of Medical Oncology, Zhongnan Hospital of Wuhan University, Wuhan, Hubei, P.R. China \\ ${ }^{10}$ School of Basic Medical Sciences, North China University of Science and Technology, Tangshan, P.R. China \\ * These authors have contributed equally to this work \\ Correspondence to: Sijun Yang, email: sijuny@vt.edu
}

Keywords: Mirol, mitophagy, insulin resistance, HFD, diabetes, Pathology Section

Received: June 26, $2017 \quad$ Accepted: August 29, $2017 \quad$ Published: September 16, 2017

Copyright: Chen et al. This is an open-access article distributed under the terms of the Creative Commons Attribution License 3.0 (CC BY 3.0), which permits unrestricted use, distribution, and reproduction in any medium, provided the original author and source are credited.

\section{ABSTRACT}

Mitochondrial function is essential to meet metabolic demand of pancreatic beta cells respond to high nutrient stress. Mitophagy is an essential component to normal pancreatic $\beta$-cell function and has been associated with $\beta$-cell failure in Type 2 diabetes (T2D). Our previous studies have indicated that mitochondrial Rho (Miro) GTPase-mediated mitochondrial dysfunction under high nutrient stress leads to NODlike receptor 3 (NLRP3)-dependent proinflammatory responses and subsequent insulin resistance. However, the in vivo mechanism by which Miro1 underlies mitophagy has not been identified. Here we show firstly that the expression of Miro is reduced in human T2D and mouse $\mathrm{db} / \mathrm{db}$ islets and in INS-1 cell line exposed to high glucose and palmitate. $\beta$-cell specific ablation of Miro1 (Miro1f/f: Rip-cre mice, or (IKO) under high nutrient stress promotes the development of hyperglycemia. $\beta$-cells from IKO mice display an inhibition of mitophagy under oxidative stress and induces mitochondrial dysfunction. Dysfunctional mitophagy in IKO mice is represented by damaged islet beta cell mitochondrial and secretory capacity, unbalanced downstream MKK-JNK signalling without affecting the levels of MEK, ERK or p38 activation and subsequently, impaired insulin secretion signaling via inhibition IRS-AKT-Foxo1 pathway, leading to worsening glucose tolerance in these mice. Thus, these data suggest that Miro1 may be responsible for mitophagy deficiency and $\beta$-cell dysfunction in T2D and that strategies target Miro1 in vivo may provide a therapeutic target to enhance $\beta$-cell mitochondrial quality and insulin secretion to ameliorate complications associated with T2D. 


\section{INTRODUCTION}

Excessive caloric or fat intake leading to obesity has been associated with beta cell dysfunction, and subsequently insulin resistance and T2D (type 2 diabetes) in human . High fat diet (HFD) feeding in mice has been reported to cause deficient islet beta cell mitophagy [1, 2]. Mitochondrial function regulated by mitophagy is essential to preserve pancreatic beta cell function and insulin secretion. Impaired beta cell function, together with deficient mitophagy, are both associated with chronic inflammation and insulin resistance [3]. Thus, insulin resistance, inflammation and pancreatic cell dysfunction are common pathological events in obese individuals [4]. Although in-depth research has been done in this area, the occurrence of complex and associated cell events and related behaviors in vivo connecting mitochondrial function and perturbed insulin secretion in T2D are not well understood. Mitochondrial activity is necessary for the process of cell proliferation and metabolism, and mitochondrial dysfunction is associated with a variety of human diseases, including cancer [5], diabetes [3] and age-related diseases [6]. Increasing evidence suggests that mitophagy maintains mitochondrial integrity and quality control not only by selectively removing dysfunctional or damaged mitochondria [7-9], but also by promoting biosynthesis of new mitochondria [10]. Recently, it has been found that before the onset of mitophagy, Cells block mitochondrial motility by causing mitochondrial Rho GTPase (Miro) degradation and ubiquitination of mitochondrial proteins to promote their identification and recruitment to autophagosomes [11-14]. Mirol is a Rho GTPase with a $\mathrm{Ca}^{2+}$ binding site [15]. Oxidative stress-induced increases in cellular $\mathrm{Ca}^{2+}$ concentrations, a primary target for insulin release; target Mirol for stop mitochondrial motility. A deficiency in Miro1-mediated mitophagy triggers triggers mtROS(mitochondrial ROS)induced NLRP3 dependent pro-inflammatory responses and is linked to T2D diseases in vitro $[12,15][9,16,17]$.

Here, we provide in vivo evidence that Miro1 ablation in islets (IKO) results in systemic inflammation in plasma, leading to pronounced hyperglycemia. Islet beta cells from IKO mice under HFD have impairment of insulin secretion. In addition, the ablation of Mirol in diabetic mice inhibited mitophagy, caused mitochondrial dysfunction, and unbalanced activation of downstream MKK-JNK pathway without affecting the levels of MEK, ERK or p38 resulted in insulin resistance via IRSAKT-Foxo1 inhibition. Thus, ablation of Miro1 in IKO mice interferes with autophagy of islet beta cells and causes mitochondrial dysfuncion and subsequent insulin secretion impairment. This study provides a mechanism for unraveling the role of Miro1 in the pathogenesis of T2D under HFD stress.

\section{RESULTS}

\section{Miro1 is decreased in pancreatic beta cells and islets under HFD stress}

Recent studies have shown that HFD can cause pancreatic beta cell dysfunction and impair insulin release in mice (1). To examine the potential involvement of Miro1 in pathophysiological processes associated with $\beta$-cell dysfunction, we detected Miro1 expression in islets from human T2D donors and the $\mathrm{db} / \mathrm{db}$ mouse models of T2D. Miro1 expression was decreased in the mitochondria in $\mathrm{db} / \mathrm{db}$ mice and T2D patients (Figure 1A). A similar result was observed in INS(rat insulinoma cell)-823/13 cells under diabetic conditions treated with $0.5 \mathrm{mM}$ PA(palmitic acid) $+20 \mathrm{mM}$ Glucose (Figure 1C). Previous studies showed that treatment with high glucose and palmitate induced Miro1 degradation via a Ca2+-dependent pathway (7). Similar to these results, a decline in Miro1 staining was observed in STZ mice (Supplementary S3) (Figure 1B). In addition, TAG content in islets was increased by more than $30.5 \%$ upon HFD feeding (Figure 1D). These observations suggest that Mirol may play a role in the pathogenesis of $\beta$-cell dysfunction.

\section{Loss of Miro1 results in obesity and insulin resistance}

Given that the STZ-diabetic mice have decreased level of Miro1 expression in islets, we created Miro1 ablation mice in the islets (IKO) (Supplementary Figure 1) and subjected them to a diabetic condition. Hematoxylin and eosin (H\&E) staining and quantification showed that the average islet size of IKO pancreas was larger approximately by $114.5 \%$ compared to floxed pancreas (Figure 2A, left and right). In response to HFD treatment, IKO mice significantly increased body weight during 4 to 24 weeks compared to mouse-specific Mirolflox / flox (Floxed) mice (Figure 2B). However, there was no significant difference in the level of energy intake between floxed and IKO mice (Supplementary Figure 2), thus eliminating the lack of Miro1-deficient as a cause of lower body weight in mice. With regard to the effect of islets Miro1 on insulin resistance, We observed fasting blood glucose (FBG) (Figure 2C), fasting serum insulin (FINS) levels (Figure 2D-2E) and homeostasis model assessment of the insulin resistance index (HOMA-IR) (Figure 2F). After HFD treatment, these levels were significantly higher in IKO mice than those in the floxed group. In addition, compared with the $\mathrm{NC}$ group, in intraperitoneal glucose tolerance test and intraperitoneal insulin tolerance test assays, the area under the curve was increased in IKO 
mice, and these effects in floxed significantly improved (Figure 2G-2H). Taken together, we find that reduction Miro1 results in obesity and disturbs insulin release in mice.

\section{Loss of Miro1 inhibits mitophagy under HFD stress}

Damaged or dysfunctional mitochondria removed by mitophagy was one mechanism to maintain mitochondrial health, and the accumulation of those abnormal mitochondria in the cell under HFD pressure may be the underlying cause of the pathogenesis of the disease. Conform to this concept, we investigated the effect of Miro1 knockdown on mitophagy in vivo. We used transmission electronmicroscopy (TEM) to confirm the double-membrane structure of autophagosomes containing undigested organelles, to observe whether HFD caused mitochondrial and autophagosome damage. As shown in Figure 3A, oval mitochondria in the control group had a complete crista structure. However, after 24 hours of incubation with HFD, mitochondria swelled and had few cristae in islet beta cells. Double membrane vesicles enclosing the mitochondria were also examined. Further, we measured the contribution of Miro1 to mitophagy in islet cells under diabetic conditions composed of $20 \mathrm{mM}$ glucose and $0.5 \mathrm{mM}$ PA incubation. We treated the islet cells with the protein synthesis inhibitor cycloheximide (CHX) to examine the rate of protein degradation. As a result, mitochondrial protein degradation rates were lower in IKO islet cells with $20 \mathrm{mM}$ glucose $+0.5 \mathrm{mM}$ PA compared to floxed islet cells. Effect of CHX treatment on protein levels of other cellular compartments such as Golgi (Golgi-58), lysosome (Lamp2), endoplasmic reticulum (calregulin), or cytosol (Gapdh, Actin) were not associated with the Mirol effects $(*, P<0.05)$. Then, to get further evidence, we detect mitophagy by transfecting multi-functional pLVX-GFP-LC3BIRES-mito-mCherry vector into islet beta cell. Green fluorescence shows autophagosomes, red fluorescence indicating mitochondria. Yellow fluorescence indicates co-localization of autophagosomes and mitochondria. Obviously, this colocalization was reduced in Mirol

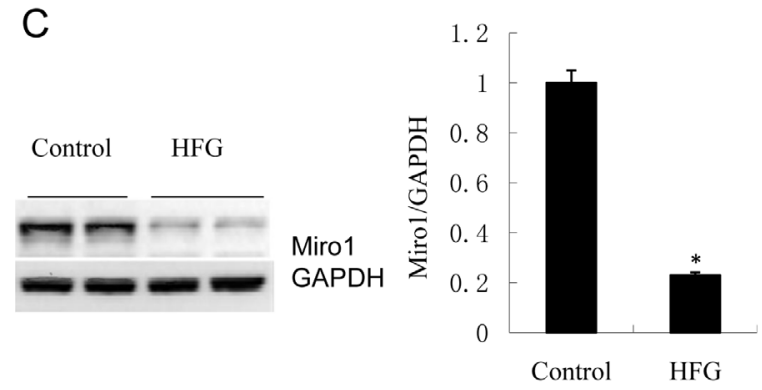

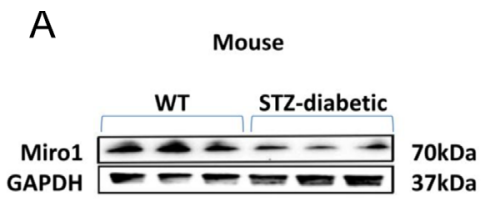

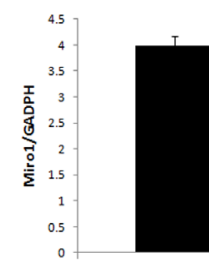

WT
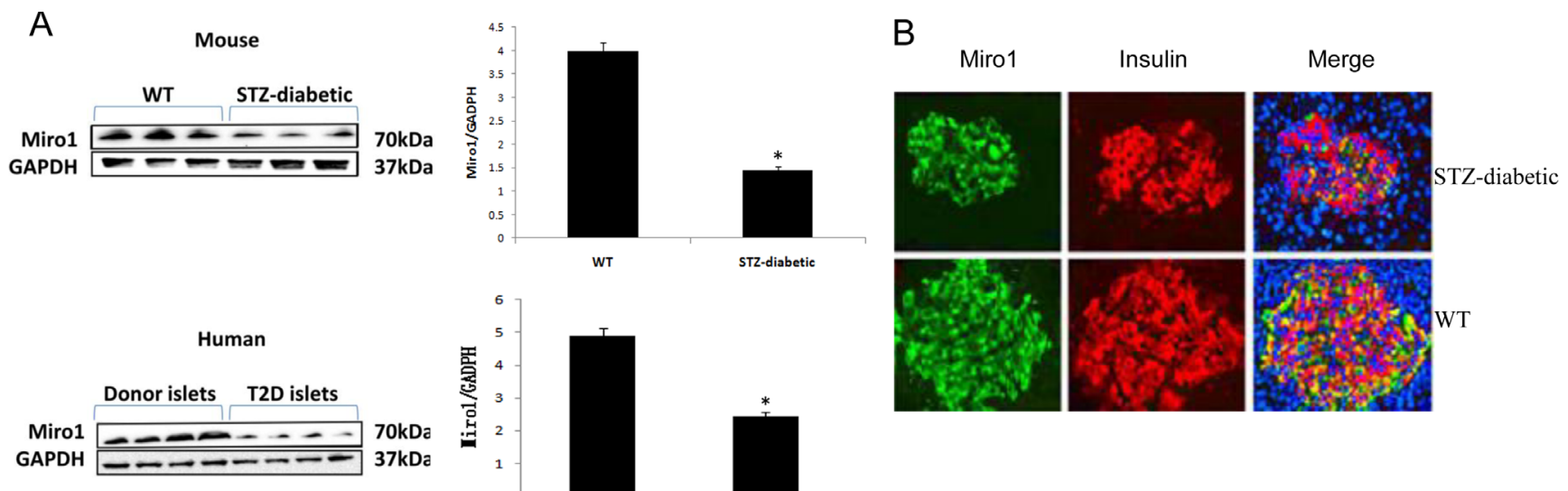
$37 \mathrm{kDa}$
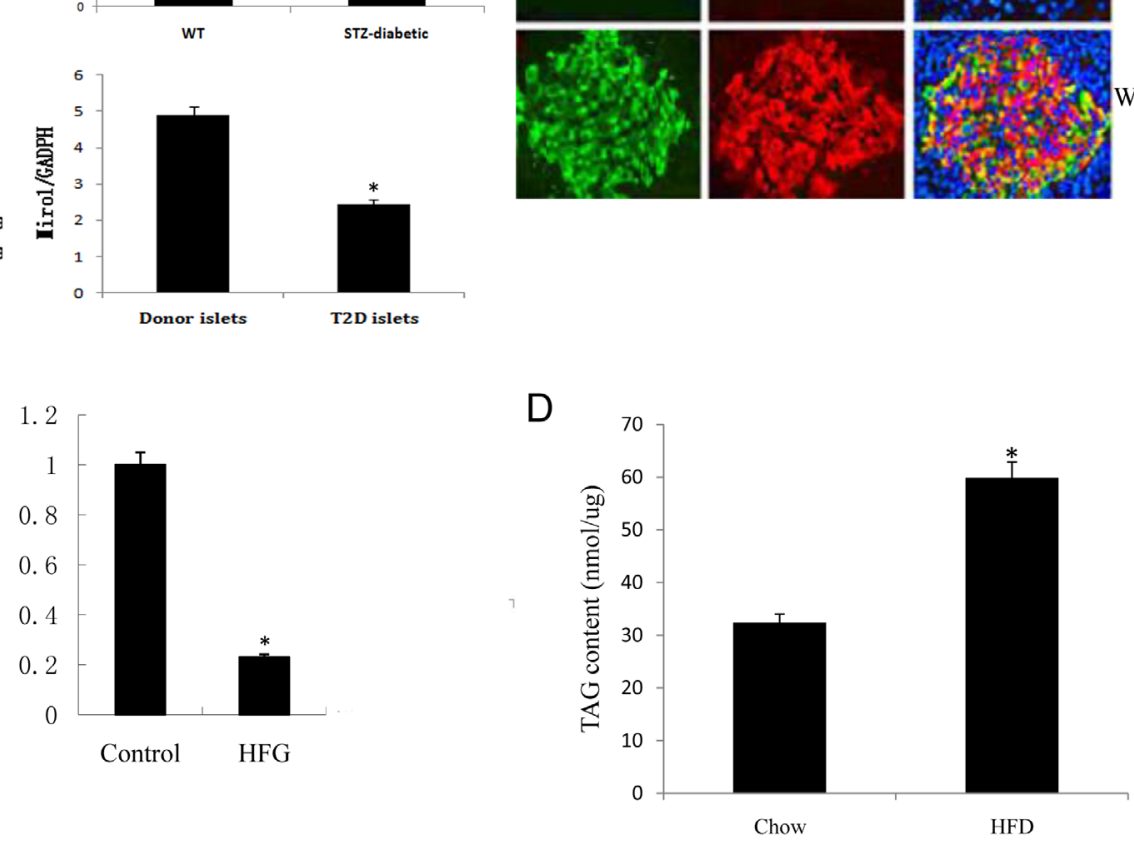

Figure 1: A. The protein level of Miro1 in islet samples from diabetic mouse model and biopsy patients with T2D. Mirol expression was normalized to that of GAPDH $\left(n=4\right.$ for normal and 7 for T2D samples, ${ }^{*} P<0.05$ versus control). B. The distribution of the Miro1 within islet cells from STZ-diabetic mouse model was analyzed using confocal microscopy. C. Miro1 protein expression in the islet of mice subjected to an HFD for 24 weeks and in NC controls $(n=5$ samples per experimental group, ${ }^{*} P<0.05$ compared with the NC group). GAPDH served as a loading control D. TAG contents in the islet of mice subjected to an HFD for 24 weeks and in NC controls ( $n=6$ samples per experimental group, $* P<0.05$ versus control). The data represent as the mean \pm SD. Statistical analysis was carried out by Student's two-tailed $t$-test. 
konckdown islet beta cells. These results demonstrated that Miro1 ablation contributed to the markedly reduced in mitophagy under diabetic conditions (Figure 3C).

\section{Loss of Miro1 promotes damaged-mitochondria- produced ROS and inflammatory responses}

To examine whether damaged mitochondrionproducing ROS and proinflammatory responses were induced under HFD stress, we used three types of mitochondria-specific markers to measure the production of mtROS, that distinguished respiring (MitoTracker deep red) which stains strongly depolarized mitochondria, total (MitoTracker green) which stains total weakly polarized mitochondrial membrane potential, and ROS-generating mitochondria (MitoSOX) (Figure 4A, left). As shown in confocal fluorescence microscopy, IKO cells had very higher MitoTracker red staining when compared to floxed cells. Thus, the density of dysfunctional mitochondria, as expressed as MitoTracker red/green ratio, was increased by $43.5 \%$ in IKO islet cells (Figure 4A, right). Previous study in our group has identified that the pancreatic islets ROS is mainly produced by mitochondria and NADPH oxidase [15], and the process of producing ROS is a feed-forward vicious cycle. Then, siRNA targeting NLRP3 suppressed IL-1b mRNA expression significantly more than a specific inhibitor of NF- $\mathrm{KB}$ (Bay11-7082) targeted NF-KB pathway in $\mathrm{HFG}$ (high fat and glucose)-treated IKO islet cells (Figure 4B). These results suggested that NLRP3 not the activation of NF-KB pathway were involved in inflammation activation under HFG diabetic condition.
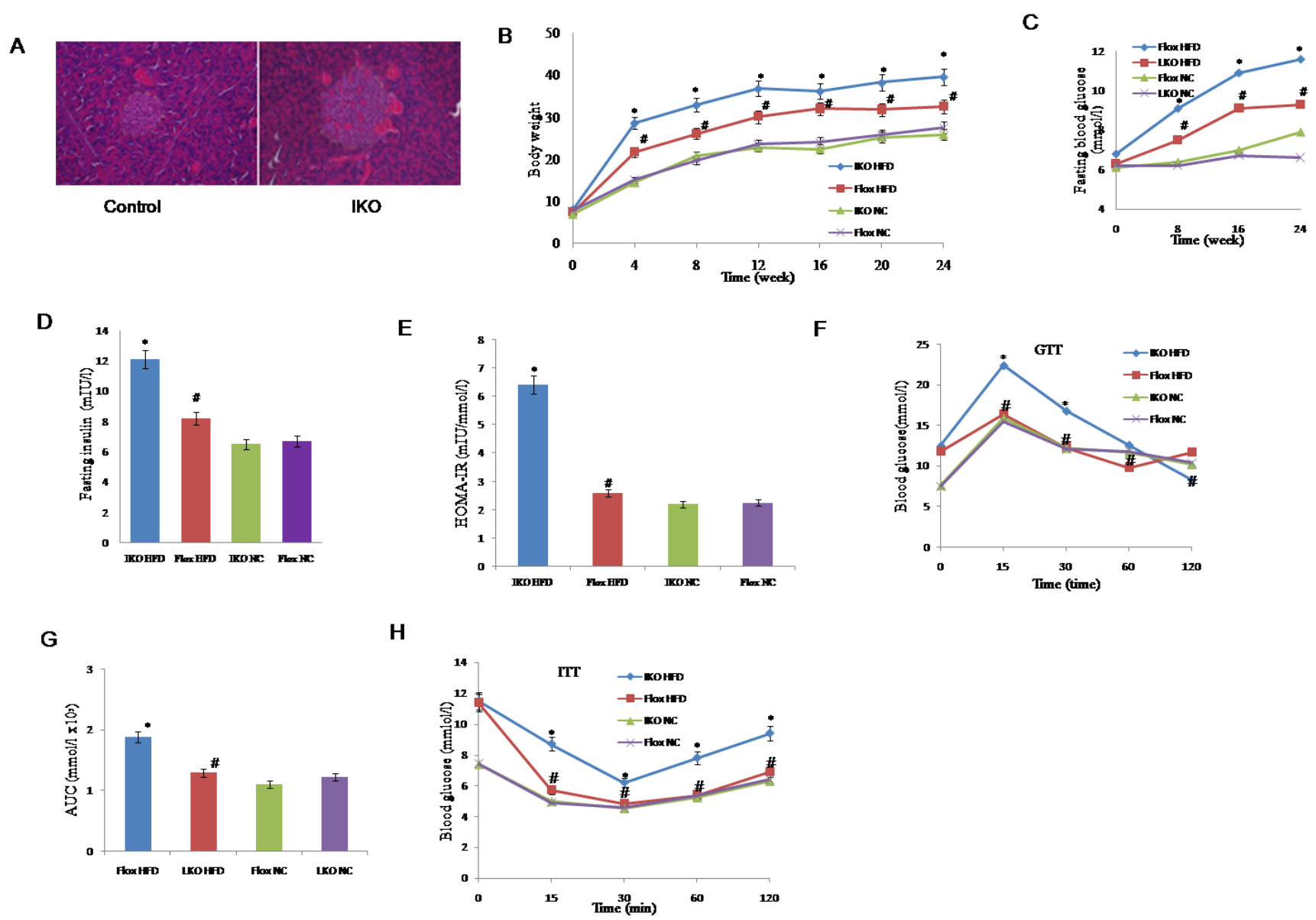

Figure 2: A. Haematoxylin and eosin staining of islet sections of IKO and floxed controls. B. Changes in the body weight of IKO and floxed mice treated with an HFD or NC for 24 weeks ( $n=13-18$ for each group per time point). C.-E. FBG, FINS and HOMA-IR in IKO or floxed mice treated with an HFD or NC for 24 weeks. FBG levels were measured every 4 week C. FINS was measured at the end point of this experiment D. HOMA-IR was calculated as HOMA-IR $=($ FBG $(\mathrm{mmol} 1-1) \times$ FINS $(\mathrm{mIU}-1)) / 22.5(n=7-13$ for each group per time point) E. F. Intraperitoneal glucose tolerance test (GTT) $(1 \mathrm{~g} \mathrm{~kg}-1)$. G.The corresponding area under the curve (AUC) of blood glucose level was calculated ( $n=7-9$ for each group). H. Intraperitoneal insulin tolerance test (ITT; 0.75 units per $\mathrm{kg}$ ) was performed on floxed and IKO mice at the 22nd or 23rd week of food administered, respectively. For A-H, ${ }^{*} P<0.05$ compared with the corresponding floxed/NC group; $\# P<0.05$ compared with the corresponding floxed/HFD group. All values are means \pm SD. Significance determined by two-way analysis of variance with general linear model procedures using a univariate approach A.-D., G. and Student's two-tailed $t$-test E., H. 
Because T2D is closely related to chronic inflammatory response [7], we measured the expression levels of inflammatory mediators in the serum samples. The serum levels of IL-1b, IL-6, TNF-a and chemokines monocyte chemotactic protein-1 (MCP-1) were significantly higher in IKO mice, but lower in floxed mice after HFD treatment (Figure 4C). Collectively, these findings show that islets from Miro1 KO exacerbate HFD-induced mitochondrial dysfunction and the related inflammatory responses.

\section{Miro1 ablation damages beta cell mitochondrial and secretory function in mice}

Next, we examined expression levels for those genes involved in mitochondrial oxidation, such as Mdh2 and Sdhb, which are involved in the TCA cycle and may regulate GSIS. We examined expression of Cpt2, Acadvl, and Hadhb (Supplementary S3), which are also related to FA oxidation [18]. We found a significant decrease in mRNA levels for all of these genes in IKO islets compared to floxed islets (Figure 5A, top left), while expression of SNAP25, Stx1a, and Vamp2, which are related to exocytosis, was not changed (Figure 5B, top right). Thus, gene expression data also support the notion of the defect in mitochondrial oxidative function in IKO islet cells. To test whether the insulin secretory defect in IKO islet cells is associated with altered gene expression, we performed quantitative RT-PCR analyses. As shown in Figure 5C, the IKO islet cells expressed lower levels of genes involved in normal beta cell secretory function such as PDX-1, NeuroD, insulin, Glut2, and urocortin3(Supplementary S3) [19]. Together, these data suggested that islet beta cell mitochondrial and secretory function was damaged by the ablation of Miro1.

\section{Unbalanced MKK-JNK signalling is involved in Miro1 impairs insulin signaling via IRS-AKT- Foxo1}

The study of the above-mentioned Miro1 involved in the regulation of insulin resistance and related pathology has prompted us to explore its underlying molecular
A

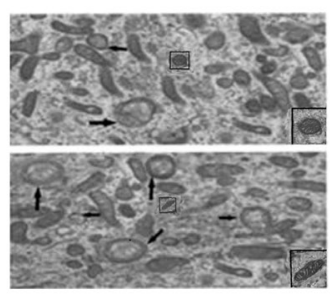

IKO

Flox
B
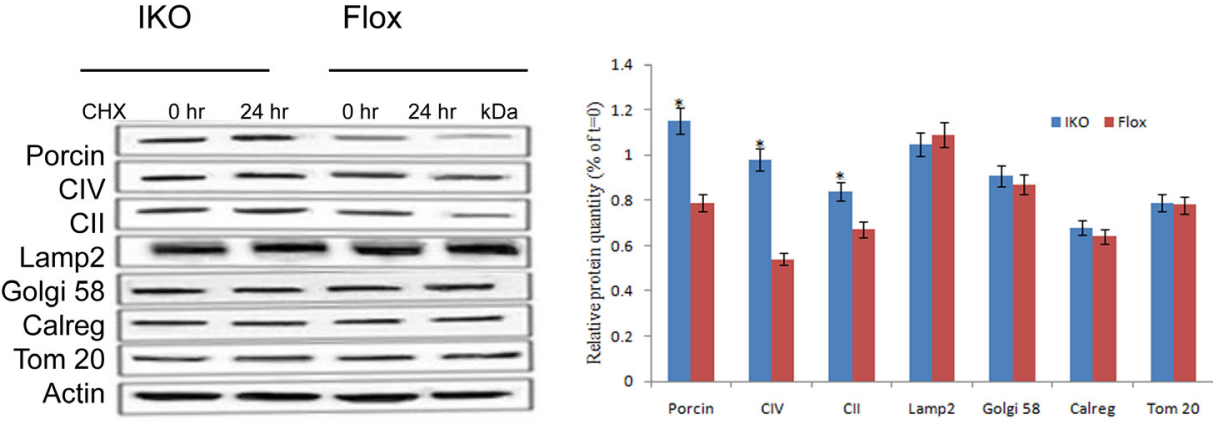

C mitoRFP GFP

DAPI Merge
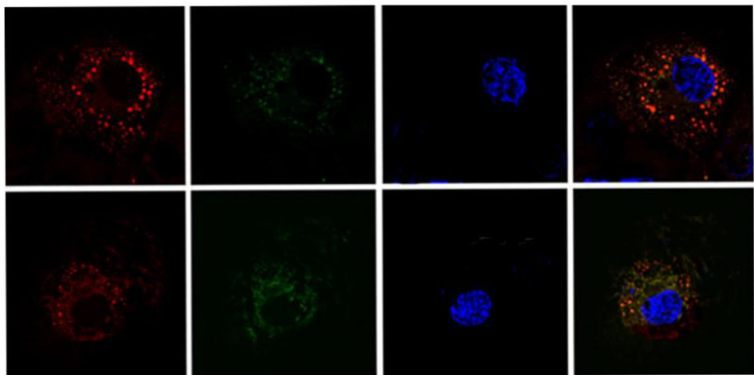

Flox-HFD

IKO-HFD

Figure 3: A. Electron microscopic analysis of mitochondria showed mitochondrial fragmentation in IKO mice compared with floxed mice. B. Protein degradation rates were measured in islet cells from IKO and floxed mice at 0 and $24 \mathrm{~h}$ of treatment with $10 \mathrm{mg} / \mathrm{ml}$ cycloheximide (CHX). Level of the mitochondrial proteins was analyzed using antibodies against porin, SDHA subunit of complex II (CII), ATP synthase (CV), and Tom20. Golgi apparatus, lysosomes, and endoplasmic reticulum were analyzed using Golgi58, Lamp2, and calregulin (calreg) antibodies. Quantification of protein levels after $24 \mathrm{~h} \mathrm{CHX}$ treatments on islet cells was showed in down panel. Blue bars are IKO, and red bars are floxed. Values are percentage of respective protein amount at $t=0(n=3)$. Dashed line represents value at $t=0$ and normalized to $100 \%$ for each protein. ${ }^{*} p<0.05$, $* * * p<0.001$. Data are presented as mean \pm SD. C.The co-localization of mito-RFP with GFP was observed using confocal microscopy. Cell nuclei were stained with DAPI, and fluorescence signals were visualized by confocal immunofluorescence microscopy. Green fluorescence indicates autophagosomes, and red fluorescence indicates mitochondria. 
mechanisms. Considering the possible involvement of MAPKs, particularly JNK and p38 MAPK cascades, in which the level of total protein and phosphorylated protein in the signal transduction was measured in the progression of this pathological condition. It was found that phosphorylated MEK, ERK or p38 did not change with the expression of Miro1 (Figure 6) while JNK signaling levels was markedly increased in the islet in response to HFD treatment in vivo (Figure 7A). Thus western blotting results showed that ERK, p38 and JNK signalling were activated simultaneously in the islets in response to HFD treatment (Figure 6), whereas the absence of Miro1 only significantly enhanced the activation of the HFDinduced MKK7-JNK-C-JUN pathway induced by in vivo (Figure 7A). Previous studies showed that the impairment of insulin sensitivity is primarily mediated by insulin signalling, particularly IRS-AKT-Foxo1. Therefore, we studied the phosphorylation of IRS1, AKT and Foxo1 in these mice that were refed for $4 \mathrm{~h}$ after overnight fasting, and observed that IKO mice reduced insulin signal transduction induced by refeeding, as demonstrated by increased phosphorylation of IRS1 at residue Ser307 and decreased phosphorylated levels of IRS1 (Tyr608), AKT, and Foxol (Figure 7B) in IKO mouse islets compared to floxed. In general, observation of IKO mice showed that insulin signaling was inhibited due to the specific lack of islets of Miro1. Examination of insulin levels during the first $30 \mathrm{~min}$ after glucose administration during the GTT indicated that, unlike IKO groups with a significant increase in insulin levels from 1.3- to 1.5-fold, NC mice were able to raise insulin levels in response to a glucose challenge (Figure 2G-2H). We also measured C-peptide levels, which, due to its longer half-life, can be a more sensitive index for insulin secretion. Indeed, C-peptide

A
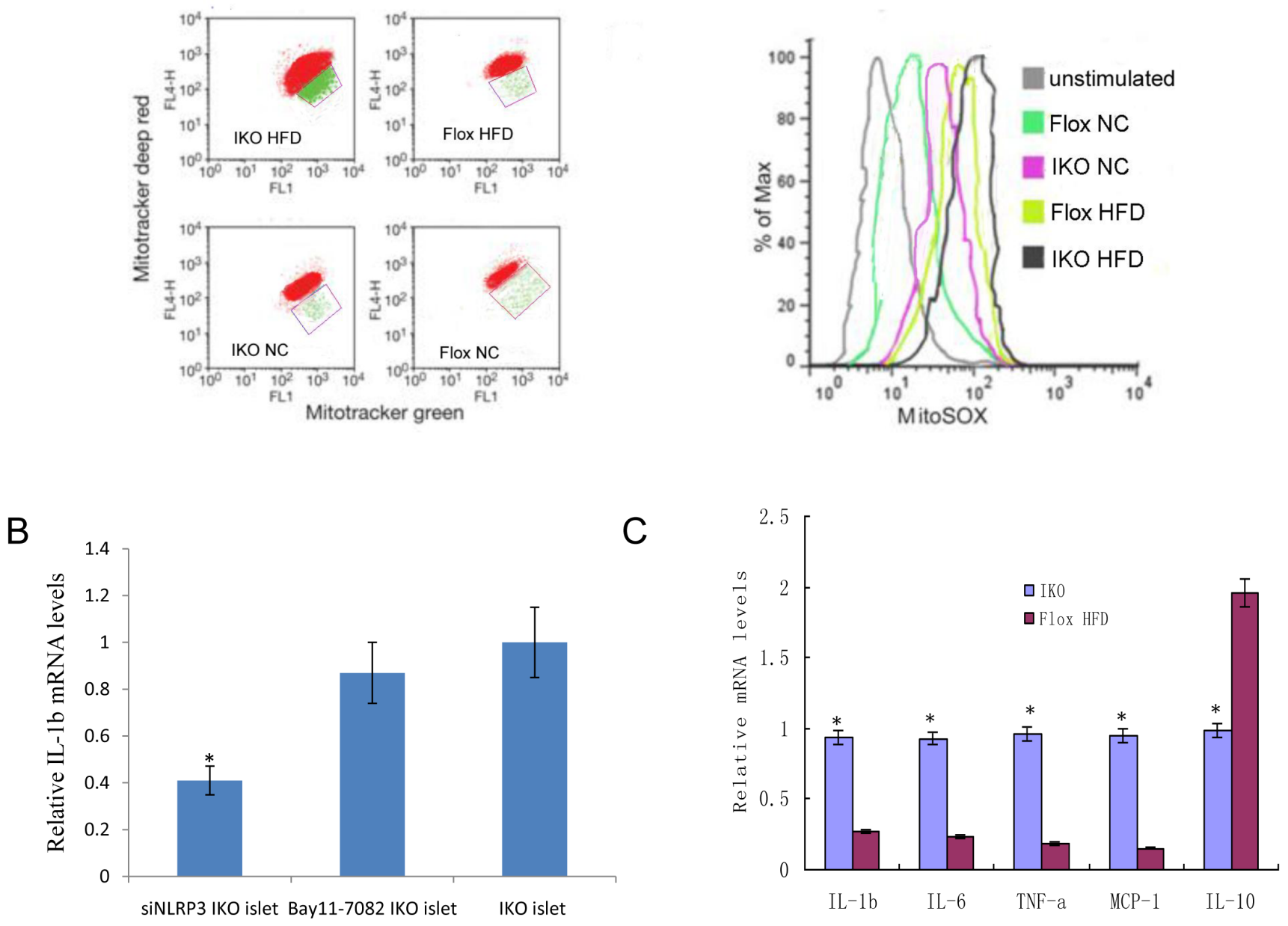

Figure 4: A. Islet cells from IKO and floxed mice under HFD/NC treatment were grown for $6 \mathrm{~h}$ and then stained with Mitotracker green and Mitotracker deep red or MitoSOX for $30 \mathrm{~min}$ and analyzed by flow cytometry. B.The IL-1b mRNA expression levels treated by siNLRP3 and Bay11-7082. C. Relative mRNA expression levels of the proinflammatory cytokines TNF- $\alpha$, IL-1 $\beta$, IL-6, IL-10 and MCP-1 were determined by qRT-PCR in islets from IKO and floxed mice. Mean \pm SD from 3 independent experiments, analyzed by one-way ANOVA following Newman-Keuls post hoc test. $* *, P<0.01$ compared to the control groups. 
levels were elevated by approximately 3-fold $30 \mathrm{~min}$ after glucose administration in NC mice, whereas the levels did not change in beta cell IKO mice under HFD (Figure 7C). These results point to the idea that insulin secretory function of beta cells may be defective in IKO mice respond to HFD treatment (Figure 7B). Unaltered glucose tolerance in our RIP-Cre mice probably was due to the pure $\mathrm{C} 57 \mathrm{BL} / 6 \mathrm{~J}$ background that we employed in our studies. Schematic illustration of molecular events and related behaviors underlying Mirolablation in islet beta cell is shown in Figure 7C: respond to a continuous HFD stress, Mirol expression is reduced in beta cells and directly inhibit mitophagy and mitochondrial dysfunction, leading to the activation of downstream MKK7-JNKC-JUN and inflammatory response. By enhancing the phosphorylation of IRS on Ser307 and destroying its downstream Foxo1 phosphorylation aggravates insulin resistance, which contribute to inflammation and insulin resistance (Figure 6).

\section{DISCUSSION}

In this study, using islet-specific Miro1-KO (IKO) mice, we identified Miro1 in pancreatic beta cell as a negative regulator of HFD-induced mitophagy deficiency, inflammatory responses, leading to beta cell secretory dysfunction. Investigations of the underlying mechanisms have shown that downregulation of the level of expression of Miro1 after a continuous challenge with an HFD, leads to imbalance activation of MKK-JNK-IRS1 ${ }^{307}$ downstream and inhibition of AKT-Foxo1 phosphorylation cascades, promotion of IKO mouse pancreatic islet insulin resistance, inflammatory response and metabolic disorders, thereby the resultant T2D (Figure 6).
A

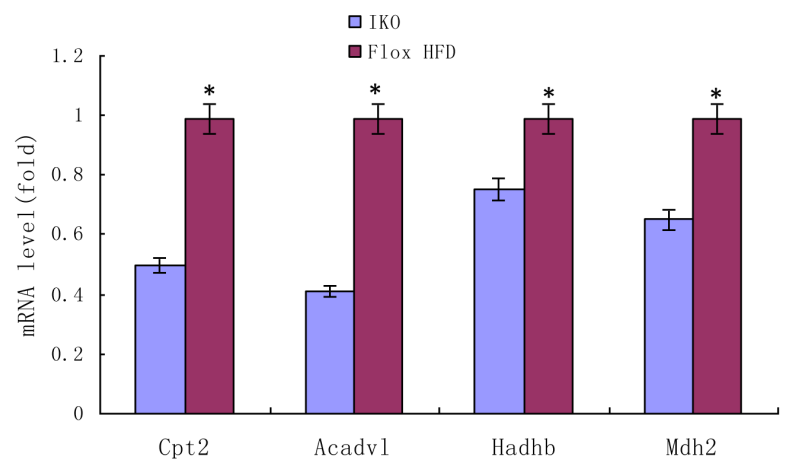

C

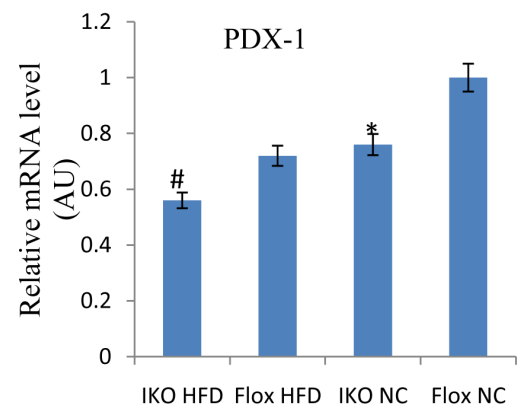

$\mathrm{F}$

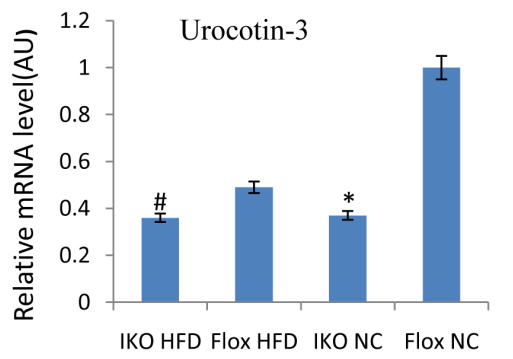

B

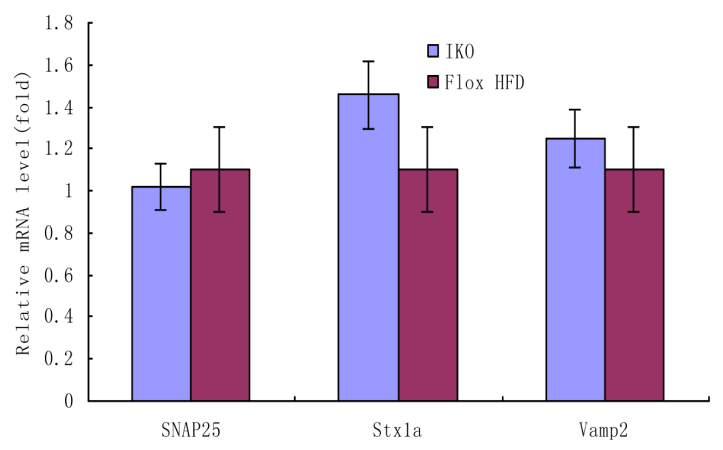

E

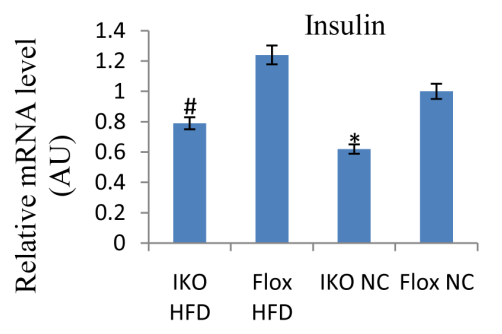

$\mathrm{H}$

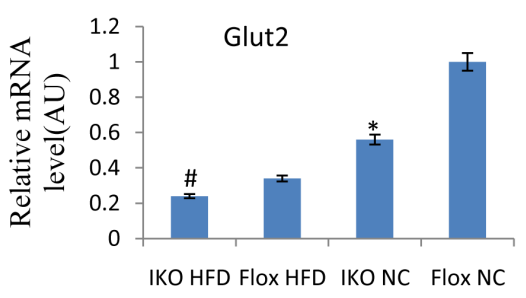

Figure 5: A.-B. RT-qPCR of mitochondrial function related genes Cpt2, Acadv1, Hadhb, and Mdh2 A. and unrelated genes SNAP25, Stxla, and Vamp2 B. in isolated islets. C.-H. mRNA level of genes PDX-1, NeuroD, Insulin, Glut2, Urocortin-3, and Cx36 involved in beta cell function and communication in islets from IKO and Floxed mice either on chow or HFD. mRNA level of each gene was normalized to $18 \mathrm{~S}$ rRNA level in the same sample. Mean $\pm \mathrm{SD}, n=6$ per group. ${ }^{*} p<$ 0.05 flox-NCD versus IKO-NCD or flox-NCD versus flox-HFD; $* * p<0.01$ flox-NCD versus IKO-NCD or flox-NCD versus IKO-HFD; \# $<0.05$ flox-HFD versus IKO-HFD. 

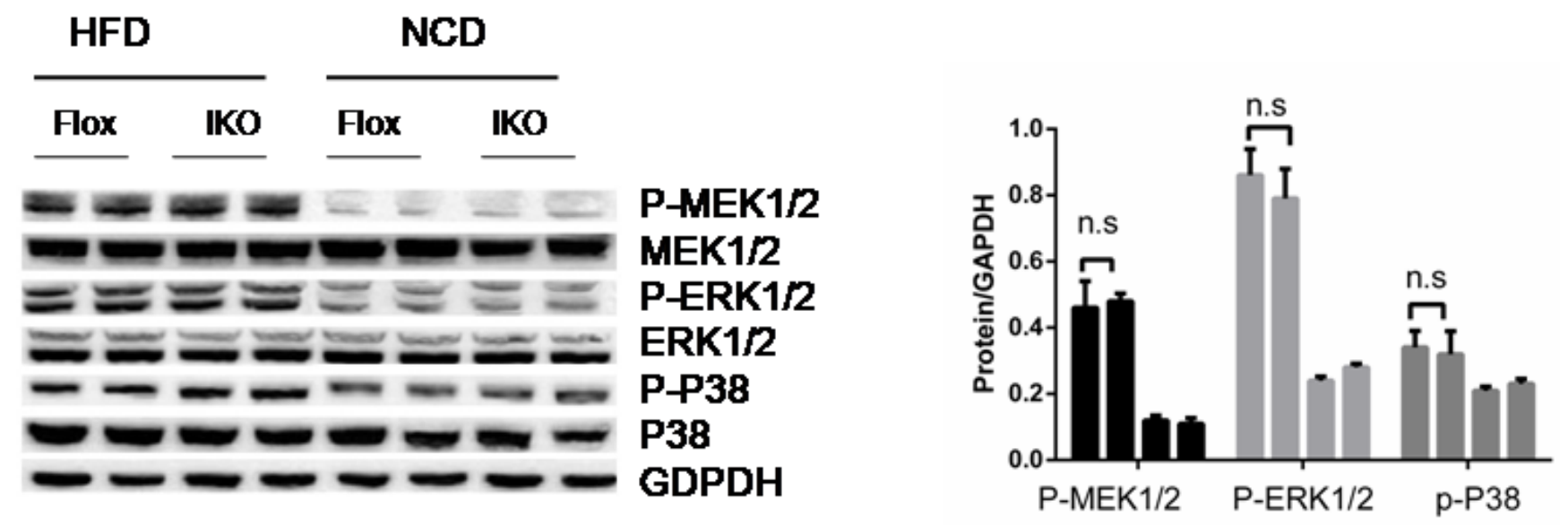

Figure 6: The expression levels of P-MEK1/2, P-ERK, P-p38 and their corresponding total proteins in the islet sample from mice of HFD- or NC-treated mice in Flox and IKO groups for 24 weeks $(n=6-7)$. n.s., no significant difference. All values are means \pm s.d. Significance determined by two-way analysis of variance with general linear model procedures using a univariate approach.
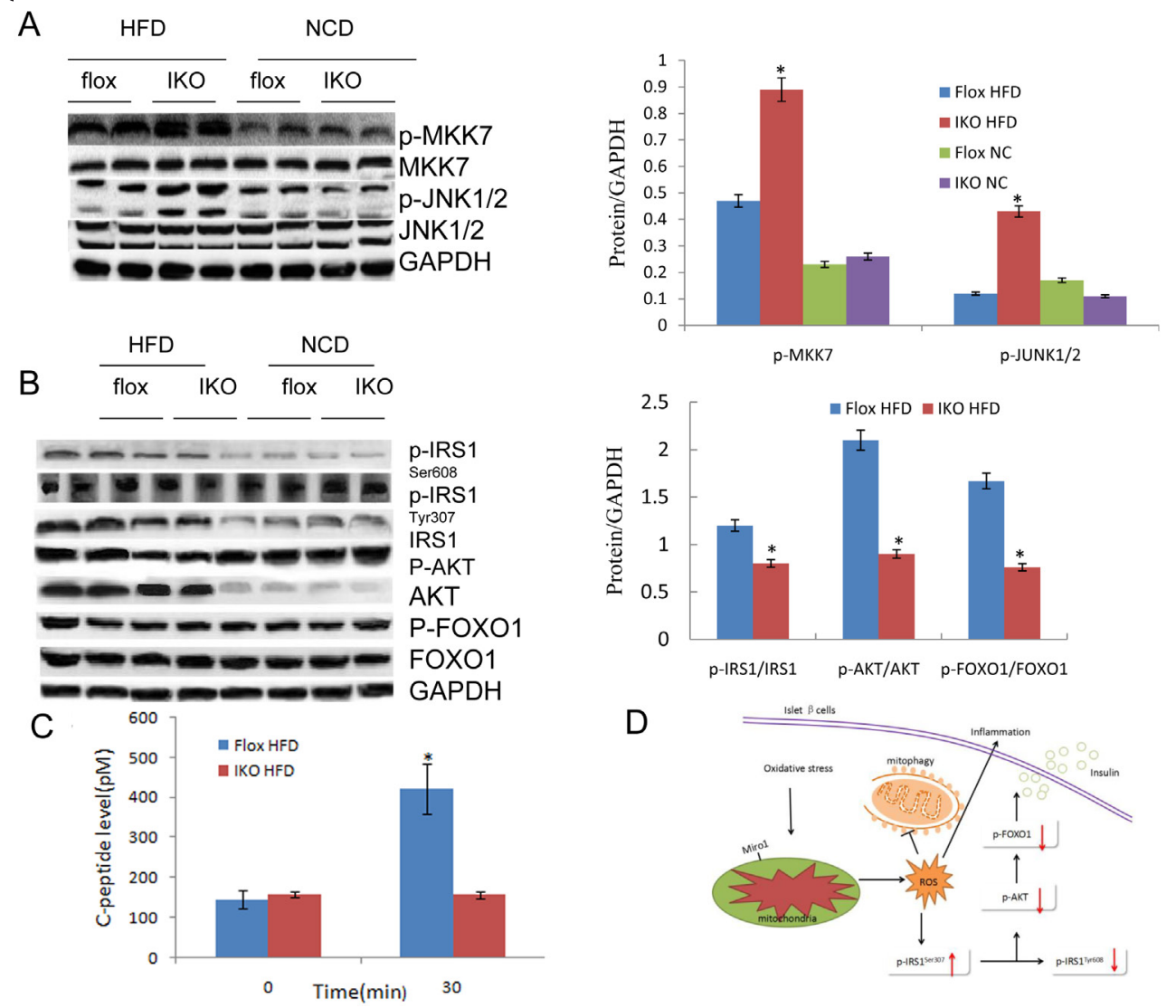

Figure 7: A.The expression levels of proteins pathway in JNK signalling in the islet sample from indicated mice. Protein expression was examined by western blotting and normalized to the indicated total protein or GAPDH expression after 4 weeks' HFD treatment ( $n=6$ samples per experimental group). B. Total and/or phosphorylated IRS1, AKT, FOXO1, and GAPDH in islet samples of HFD-fed mice that were refed for $4 \mathrm{~h}$ after overnight fasting and NC mice under fasting state at the end of 24 weeks. GAPDH serves as the loading control ( $n=4$ samples per experimental group). All values are means \pm s.d. Significance determined by two-way analysis of variance with general linear model procedures using a univariate approach. C. C-peptide levels in IKO and Flox mice. D. Schematic illustration of cellular events underlying Miro1-mediated insulin resistance. In response to a continuous challenge with HFD, Mirol expression is decreased in islet beta cells leading to the activation of mtROS production and mitophagy inhibition, thereby promoting inflammatory response. The activated JNK further aggravates insulin resistance through enhancing IRS phosphorylation at Ser307 and disrupts its downstream AKTFoxo1 phosphorylation, which contribute to inflammation and insulin resistance, and the resultant T2D. 
The mitochondria in beta cells play a key role in producing ROS, regulating intracellular signaling and controlling cell death [20]. Metabolic stress-induced mitochondrial damage and ROS overproduction has been shown to lead to beta cell dysfunction and further develop into T2D [15, 21]. The presence of ROS in HFD stress indicates that mitochondria are the major source of ROS in islet cells after HFD treatment because the effect of DPI (NADPH oxidase inhibitors) on the elimination of HFDinduced ROS production is negligible [22]. It has been demonstrated that mtROS activates NLRP3 inflammasome together with fatty acids in vitro, leading to the release of active IL-1 $\beta$ and the production of IL-1-dependent cytokines and chemokines. In our previous study, it was confirmed that Bay11-7082 did not participate in the initiation of NLRP3 inflammatory body, so the NLRP3dependent proinflammatory response driven by sustained mtROS production was not caused by NF-Kb activation [15] . Consistent with previous reports, in the present study, HFD stress reduced the expression of Islet Miro1, thereby promoting the damage of mitochondrial-induced mtROS production and loss of membrane potential, further leading to cytokines (TNF- $\alpha$, IL-6 and IL- $1 \beta$ ) and chemokine (MCP-1) in islet $\beta$ cells of IKO mice [23]. In addition, our findings confirmed that Mirol ablation damages beta cell function examined by Cpt2, Acadvl, and Hadhb led to inflammasome activation interfering with mitochondrial secretory function by detecting PDX1, NeuroD, insulin, Glut2, and urocortin3, suggesting a therapeutic promising of Miro1 for mtROS-related T2D.

Mitophagy is an important mechanism for the elimination of damaged mitochondria and the protection of mitochondrial health, and plays a key role in protecting beta cells under metabolic stress conditions $[9,17][16$, 24]. Mitophagy deficiency is known to lead to both mitochondrial dysfunction and defects in mitochondrial dynamics related to Miro1 [25, 26] [15]. We examined the removal of damaged mitochondria by mitophagy over time by measuring the protein levels of mitochondrial markers on the inner, outer membrane, matrix, and intermembrane space. Knockdown of Miro1 in IKO mice significantly reduced the mitochondrial removal process, and all of the above mitochondrial markers disappeared in control islet cells faster than IKO islet cells. This indicates that mitophagy activity is weaker after Mirol knockout. To further confirm this result, we monitored the autophagolysosome formation under an electric microscope. We found that knockout of Mirol resulted in the accumulation of mitochondria that were damaged in the perinuclear region compared to control of islet cells, this is consistent with previous report that Mirol is an essential for mitochondrial autophagy [27, 28]. Recent study shows that Miro1 involved as part of a mitophagy pathway by arresting of mitochondrial motility, helps to quarantine a depolarized mitochondrion or mitochondrial fragment prior to phagocytosis $[29,30]$, so that the damage caused by the released mtROS will be limited to a smaller area. Removal of Miro1 from beta-cell mitochondria will detaches kinesin from its surface [30]. This confirms our observations of defective insulin release, activated inflammation, and oxidative stress related to islet cell mitophagy function in IKO mice. This may be at the stage of the pathway at which decreased level of Miro1 occurs under more than 4-week sustained HFD stress and mitophagy impairs after initial compensation. Our findings underscore the significance of Miro1-associated mitophagy for providing adequate energy for a change in energy demand and clearing damaged mitochondria under late-event (4-24 week) of HFD stress.

Insulin function is synergistically coordinated by molecular events associated with IRS [31]. On the basis of previous studies and our current findings, JNK1 effectively promotes IRS1 phosphorylation of serine 307 after activation by Miro1 and subsequently induces inhibition of IRS1 tyrosine phosphorylation, which leads to compromised capacity of IRS1 to bind to insulin receptors and decreased AKT phosphorylation [32]. Akt phosphorylates Foxol and inhibits the transcriptional activity of Foxo1, which regulates various physiological functions such as energy metabolism. Akt $\rightarrow$ Foxol phosphorylation mediates many biological responses to insulin, and it serves as an indicator of insulin sensitivity [33]. Consistent with our results, it has been demonstrated that deletion of IRS1 and IRS2 genes in mice prevented activation of liver Akt-Foxo1 phosphorylation and led to the development of diabetes [34]. However, the molecular pathway of Miro1-regulated IRS-Akt-Foxo1 remains to be further elucidated [35].

In conclusion, this study determined a loss of Miro1-mediated effect on abnormal islet beta cell function in vivo which promotes unbalanced downstream MKKJNK activation and IRS-AKT-Foxol inhibition, thereby promoting insulin resistance, mitophagy deficiency, and inflammatory response in the islet on an HFD stimulus. Thus, targeting Mirol in the islet might be a promising therapeutic treatment for insulin resistance and related metabolic diseases.

\section{MATERIALS AND METHODS}

\section{Mice}

Generation of Miro1f/ + mice is described previously (18). The $\mathrm{db} / \mathrm{db}$ and RIP-cre mice used in the present study were purchased from the biomedical institute of Nanjing University (stock no.: N000098, N000117). All experimental procedures were approved by Wuhan University Animal Care and Use Committee, and were conducted in full accordance with the Guide for the Care and Use of Laboratory Animals. All controls were 
phenotypic wild-type (WT) littermates of the mutant animals (Miro1F/+, RIPcre+/+). Male mice of 4-12 weeks of age (20-34 g) were used in these experiments. The mice were bred in a standard environment with a 12-h light/dark cycle. The diabetic model was established in mice through feeding a HFD (protein, 18.1\%; fat, 61.6\%; carbohydrates, 20.3\%; D12492, Research Diets, NJ, USA) continuously for 24 weeks. Mice administered an NC diet (protein, $18.3 \%$; fat, $10.2 \%$; carbohydrates, $71.5 \%$; D12450B, Research Diets) served as controls. Food and water were provided ad labium. The body weight (BW) and fasting blood glucose (FBG) level of mice was examined every 4 weeks. Immediately after death, the pancreases were surgically removed, and the islets isolated by collagenase dispersion. Krebs-Ringer bicarbonate buffer was used for isolation and pooling of the islets (19) .

\section{Cell culture and transfection}

Islet cells or rat insulinoma (INS-1) $(823 / 13)$ cells were grown in RPMI 1640 medium. For the different experiments, cells were cultured in 6-well plates until reaching $80 \%$ confluence before additional treatment. The samples were incubated for $6 \mathrm{~h}$ or $12 \mathrm{~h}\left(37^{\circ} \mathrm{C}\right.$ and $5 \%$ $\mathrm{CO} 2$ ) in the presence of $11 \mathrm{mmol} / 1$ glucose, $0.05 \mathrm{mmol} / 1$ palmitate, or/and $10 \mu \mathrm{mol} / 1$ diphenylene iodonium (DPI), an NADPH oxidase inhibitor, Bay11-7082 (6.3 $\mu \mathrm{m})$ for $1 \mathrm{~h}$ where indicated (20). The pmCherry-GFP-LC3B and pLVX-IRES-mCherry vectors used in the experiment were purchased from Addgene (Cambridge, MA, USA), and the construction of the infected plasmids pLVX-GFPLC3B-IRES-mito-mCherry were described previously [36]. Lentiviral production was achieved through calcium phosphate transfection of four plasmids, according to the manufacturer's instructions [37].

\section{Glucose and insulin tolerance tests}

GTT and ITT performed upon intraperitoneal injection of $2 \mathrm{mg} / \mathrm{g}$ BW of D-glucose or $0.75 \mathrm{mU} / \mathrm{g} \mathrm{BW}$ of insulin, respectively, as previously described (22). Tail vein blood was collected for measurements.

\section{Metabolic assays and serum cytokine analyses}

FBG and fasting serum insulin (FINS) levels were examined after mice had fasted for $6 \mathrm{~h}$ by using a glucometer (Life Scan, PA, USA) and by ELISA (Millipore, MA, USA), respectively, and the insulin resistance index (HOMA-IR) was calculated with the equation (FBG (mmol 1-1) x FINS(mIU 1-1))/22.5. Blood glucose levels were examined at $0,15,30,60$, and 120 min after injection. ELISA (Invitrogen, CA, USA) examined the concentrations of cytokines (TNF-a, IL-1b,
IL-6, and IL-10, and monocyte chemotactic protein- 1) in the serum. Commercial kits were employed to measure the TG in the islet (290-63701, Tokyo, Japan) according to the manufacturer's instructions.

\section{H\&E staining, immunostaining}

For immunostaining, islets were handpicked under a stereomicroscope and fixed in a $10 \%$ formaldehyde solution. Islets were stained with primary antibodies against insulin followed by Alexa Fluor 488 secondary antibody staining and DAPI was used to visualize nuclei. Sections or islets were visualized with an AxioImager.

\section{Quantitative real time PCR (qRT-PCR)}

Total RNA was extracted using Trizol Reagent (Invitrogen, USA) and cDNA was synthesized using iScript $^{\mathrm{TM}}$ cDNA Synthesis Kit (Bio-Rad, USA) according to the manufacturer's instructions. mRNA expression was normalized to that of $18 \mathrm{~S}$ mRNA.

\section{Confocal microscopy}

Fixed and permeabilized islets cells were used for confocal microscopy as described previously with modification (23). The fixed cells were blocked with normal goat serum, probed with mouse anti-Miro1 or insulin monoclonal antibodies and stained with Texas red-conjugated goat anti-mouse IgG antibodies (KPL, Gaithersburg MD). Finally, the cover glass was washed, mounted and examined using the confocal laser microscope.

\section{Detection of reactive oxygen species}

Treated islets were washed in PBS and placed in PBS containing $2.5 \mu \mathrm{M}$ MitoSOX (to measure mitochondrial ROS production) and/or $10 \mu \mathrm{m}$ 6-carboxy-2', 7'-dichlorodihydrofluorescein diacetate, di(acetoxymethyl ester) (DCF-DA, Invitrogen, Carlsbad, CA) (to measure total cellular ROS) for $30 \mathrm{~min}$ at $37^{\circ} \mathrm{C}$. Following a PBS wash and re-incubation in PBS for $1 \mathrm{~h}$ at $37^{\circ} \mathrm{C}, 10 \mu \mathrm{M}$ Hydrogen Peroxide $\left(\mathrm{H}_{2} \mathrm{O}_{2}\right)$ was used for $2 \mathrm{~h}$ as a positive control. Fluorescence was measured on a SpectraMax M5 plate reader (Molecular Devices, Sunnyvale, CA); emission wavelength 480nm; excitation wavelength $530 \mathrm{~nm}$.

\section{Western blotting}

Cell lysates were separated by electrophoresis prior to transfer to PVDF membranes. Data were 
normalized relative to actin or GAPDH. The following primary antibodies were used for Western blots and immunostaining: anti-LC3 (Cell Signaling, 4108), antiTom20 (SantaCruz, sc-17764); anti-calregulin (SantaCruz, sc-6468-R); anti-Gapdh (Abcam, ab9483); anti-Golgi58 (Abcam, ab27043); rabbit anti-Miro1 (Sigma, HPA01068); p-JNK (Cell Signaling, 4668); JNK (Cell Signaling, 9252); p-IRS1ser307 (Cell Signaling, 2831); IRS1 (Cell Signaling, 2832); ERK1/2, p38, MEK1/2 antibodies ( New England Biolabs, p44/42, 9102L, 4694S), p-AKTSer473 (Cell Signaling, 4060); AKT (Cell Signaling, 4691); Antibody against p-IRS1Tyr608 (Cell Signaling, 09-432); anti-p-POXO1 (ORIGENE, TA323072). Anti-IL1 beta antibody (Abcam, ab2105); anti-IL6 antibody (Abcam, ab6672); Anti-monocyte chemotactic protein-1(MCP)-1 antibody (Abcam, ab9669); Anti-TNF alpha antibody (Abcam, ab9635). Alexa Fluor-conjugated antibodies (Molecular Probes, A21057, A21076, A21096) were used as secondary antibodies.

\section{Mitochondrial isolation}

Mitochondria were isolated using mitochondrial isolation kit according to the manufacturer's instructions (Pierce). Briefly, cells were homogenized and then centrifuged at $750 \mathrm{x}$ g for $10 \mathrm{~min}$ at $4^{\circ} \mathrm{C}$. The supernatant was further centrifuged at $12,000 \mathrm{x}$ g for $15 \mathrm{~min}$ at $4^{\circ} \mathrm{C}$. The pellet was then washed and kept as the mitochondrial fraction. The supernatant was further centrifuged at $100,000 \times \mathrm{g}$ for $1 \mathrm{~h}$ at $4^{\circ} \mathrm{C}$ and designated as the cytosolic fraction.

\section{Electron microscopy}

Islets from IKO and control mice were cultured in Aclar embedding film (2-mm thickness, Electron Microscopy Sciences, PA, USA), fixed in $2.5 \%$ glutaraldehyde and $4 \%$ sucrose in a $0.05 \mathrm{~mol} / 1$ phosphate buffer, $\mathrm{pH}$ 7.4, and examined with a JEOL 1200EX electron microscope (JEOL, Tokyo, Japan) as described previously.

\section{Flow cytometry}

MitoSOX, MitoTracker green and red, and DCFDA staining were done according to manufacturer's instructions (Invitrogen). Data were acquired with a FACS Calibur flow cytometer (BD Biosciences).

\section{Statistical analysis}

All values are expressed as mean \pm SD. Differences between means were analyzed using either one-way or two-way ANOVA followed by Newman-Keuls post-hoc testing for pair-wise comparison using SPSS. The null hypothesis was rejected when the $P$-value $<0.05$.

\section{Abbreviations}

T2D, type 2 diabetes; Miro1, mitochondrial rho GTPase 1; NLRP3, NOD-like receptor 3; IKO, Miro1 ablation in islets; HFD, high fat and diet; mtROS, mitochondrial ROS; INS, rat insulinoma cell; PA, palmitic acid; HFG, high fat and glucose

\section{Author contributions}

S.J.Y conceived of, designed, and performed experiments, interpreted results, and drafted and reviewed the manuscript. J.W.L and C.Y.L. designed and performed experiments and interpreted results Y.B. Y. performed and analyzed results of human islet studies. D J.K, X.L.M., Z.W.,X and S.J. Z. analyzed and and reviewed the manuscript. F.L.Z. and L.W.C.C designed the mouse model and reviewed the manuscript. Y.C.W. provided mice and edited and reviewed the manuscript.

\section{CONFLICTS OF INTEREST}

The authors declare no competing financial interests.

\section{FUNDING}

This work was supported by grants from the National Natural Science Foundation of China (No. 81670747), Wuhan University top-notch talent fund (2042016kf0149), Hubei Provincial Natural Fund key projects (2015CFA075), and Wuhan University outstanding talent start fund (907/410100006).

\section{REFERENCES}

1. Ehses JA, Meier DT, Wueest S, Rytka J, Boller S, Wielinga PY, Schraenen A, Lemaire K, Debray S, Van Lommel L, Pospisilik JA, Tschopp O, Schultze SM, et al. Tolllike receptor 2-deficient mice are protected from insulin resistance and beta cell dysfunction induced by a highfat diet. Diabetologia. 2010; 53:1795-806. https://doi. org/10.1007/s00125-010-1747-3

2. Mottillo EP, Desjardins EM, Crane JD, Smith BK, Green AE, Ducommun S, Henriksen TI, Rebalka IA, Razi A, Sakamoto K, Scheele C, Kemp BE, Hawke TJ, et al. Lack of Adipocyte AMPK Exacerbates Insulin Resistance and Hepatic Steatosis through Brown and Beige Adipose Tissue Function. Cell Metab. 2016; 24:118-29. https://doi. org/10.1016/j.cmet.2016.06.006

3. Baltrusch S. Mitochondrial network regulation and its potential interference with inflammatory signals in 
pancreatic beta cells. Diabetologia. 2016; 59:683-87. https://doi.org/10.1007/s00125-016-3891-x

4. Marzetti E, Calvani R, Cesari M, Buford TW, Lorenzi M, Behnke BJ, Leeuwenburgh C. Mitochondrial dysfunction and sarcopenia of aging: from signaling pathways to clinical trials. Int J Biochem Cell Biol. 2013; 45:2288-301. https:// doi.org/10.1016/j.biocel.2013.06.024

5. Mills EL, Kelly B, O’Neill LA. Mitochondria are the powerhouses of immunity. Nat Immunol. 2017; 18:488-98. https://doi.org/10.1038/ni.3704

6. Mora AL, Bueno M, Rojas M. Mitochondria in the spotlight of aging and idiopathic pulmonary fibrosis. J Clin Invest. 2017; 127:405-14. https://doi.org/10.1172/JCI87440

7. Yang S, Xia C, Li S, Du L, Zhang L, Zhou R. Defective mitophagy driven by dysregulation of rheb and KIF5B contributes to mitochondrial reactive oxygen species (ROS)-induced nod-like receptor 3 (NLRP3) dependent proinflammatory response and aggravates lipotoxicity. Redox Biol. 2014; 3:63-71. https://doi.org/10.1016/j. redox.2014.04.001

8. Bin-Umer MA, McLaughlin JE, Butterly MS, McCormick $\mathrm{S}$, Tumer NE. Elimination of damaged mitochondria through mitophagy reduces mitochondrial oxidative stress and increases tolerance to trichothecenes. Proc Natl Acad Sci USA. 2014; 111:11798-803. https://doi.org/10.1073/ pnas. 1403145111

9. Soleimanpour SA, Ferrari AM, Raum JC, Groff DN, Yang J, Kaufman BA, Stoffers DA. Diabetes Susceptibility Genes Pdx1 and Clec16a Function in a Pathway Regulating Mitophagy in $\beta$-Cells. Diabetes. 2015; 64:3475-84. https:// doi.org/10.2337/db15-0376

10. Zhu J, Wang KZ, Chu CT. After the banquet: mitochondrial biogenesis, mitophagy, and cell survival. Autophagy. 2013; 9:1663-76. https://doi.org/10.4161/auto.24135

11. Kazlauskaite A, Kelly V, Johnson C, Baillie C, Hastie CJ, Peggie M, Macartney T, Woodroof HI, Alessi DR, Pedrioli PG, Muqit MM. Phosphorylation of Parkin at Serine65 is essential for activation: elaboration of a Mirol substratebased assay of Parkin E3 ligase activity. Open Biol. 2014; 4:130213. https://doi.org/10.1098/rsob.130213

12. Macaskill AF, Rinholm JE, Twelvetrees AE, ArancibiaCarcamo IL, Muir J, Fransson A, Aspenstrom P, Attwell D, Kittler JT. Miro1 is a calcium sensor for glutamate receptordependent localization of mitochondria at synapses. Neuron. 2009; 61:541-55. https://doi.org/10.1016/j. neuron.2009.01.030

13. Shlevkov E, Kramer T, Schapansky J, LaVoie MJ, Schwarz TL. Miro phosphorylation sites regulate Parkin recruitment and mitochondrial motility. Proc Natl Acad Sci USA. 2016; 113:E6097-106. https://doi.org/10.1073/pnas.1612283113

14. Tang BL. MIRO GTPases in Mitochondrial Transport, Homeostasis and Pathology. Cells. 2015; 5:E1. https://doi. org/10.3390/cells5010001

15. Gao J, Sang M, Zhang X, Zheng T, Pan J, Dai M, Zhou
L, Yang S. Miro1-mediated mitochondrial dysfunction under high nutrient stress is linked to NOD-like receptor 3 (NLRP3)-dependent inflammatory responses in rat pancreatic beta cells. Free Radic Biol Med. 2015; 89:32232. doi: 10.1016/j.freeradbiomed.2015.09.002

16. Hoshino A, Ariyoshi M, Okawa Y, Kaimoto S, Uchihashi M, Fukai K, Iwai-Kanai E, Ikeda K, Ueyama T, Ogata T, Matoba S. Inhibition of p53 preserves Parkin-mediated mitophagy and pancreatic $\beta$-cell function in diabetes. Proc Natl Acad Sci USA. 2014; 111:3116-21. https://doi. org/10.1073/pnas.1318951111

17. Soleimanpour SA, Gupta A, Bakay M, Ferrari AM, Groff DN, Fadista J, Spruce LA, Kushner JA, Groop L, Seeholzer SH, Kaufman BA, Hakonarson H, Stoffers DA. The diabetes susceptibility gene Clec16a regulates mitophagy. Cell. 2014; 157:1577-90. https://doi.org/10.1016/j. cell.2014.05.016

18. Roberts KA, Calloway C. Characterization of mitochondrial DNA sequence heteroplasmy in blood tissue and hair as a function of hair morphology. J Forensic Sci. 2011; 56:4660. https://doi.org/10.1111/j.1556-4029.2010.01540.x

19. Lee YS, Morinaga H, Kim JJ, Lagakos W, Taylor S, Keshwani M, Perkins G, Dong H, Kayali AG, Sweet IR, Olefsky J. The fractalkine/CX3CR1 system regulates $\beta$ cell function and insulin secretion. Cell. 2013; 153:413-25. https://doi.org/10.1016/j.cell.2013.03.001

20. Szendroedi J, Phielix E, Roden M. The role of mitochondria in insulin resistance and type 2 diabetes mellitus. Nat Rev Endocrinol. 2011; 8:92-103. https://doi.org/10.1038/ nrendo. 2011.138

21. Martin SD, McGee SL. The role of mitochondria in the aetiology of insulin resistance and type 2 diabetes. Biochim Biophys Acta. 2014; 1840:1303-12. https://doi. org/10.1016/j.bbagen.2013.09.019

22. Kowluru A. Adenine and guanine nucleotide-specific succinyl-CoA synthetases in the clonal beta-cell mitochondria: implications in the beta-cell high-energy phosphate metabolism in relation to physiological insulin secretion. Diabetologia. 2001; 44:89-94. https://doi. org/10.1007/s001250051584

23. Farrell NJ, Norris GH, Ryan J, Porter CM, Jiang C, Blesso $\mathrm{CN}$. Black elderberry extract attenuates inflammation and metabolic dysfunction in diet-induced obese mice. Br J Nutr. 2015; 114:1123-31. https://doi.org/10.1017/ S0007114515002962

24. MacDonald MJ, Ade L, Ntambi JM, Ansari IU, Stoker SW. Characterization of phospholipids in insulin secretory granules and mitochondria in pancreatic beta cells and their changes with glucose stimulation. J Biol Chem. 2015; 290:11075-92. https://doi.org/10.1074/jbc.M114.628420

25. Vaccaro V, Devine MJ, Higgs NF, Kittler JT. Miro1dependent mitochondrial positioning drives the rescaling of presynaptic $\mathrm{Ca} 2+$ signals during homeostatic plasticity. EMBO Rep. 2017; 18:231-40. https://doi.org/10.15252/ embr.201642710 
26. Kittler J. Regulation of mitochondrial trafficking, function and quality control by the mitochondrial GTPases Miro1 and Miro2. Springerplus. 2015 (Suppl 1); 4:L33. https://doi. org/10.1186/2193-1801-4-S1-L33

27. Hsieh CH, Shaltouki A, Gonzalez AE, Bettencourt da Cruz A, Burbulla LF, St Lawrence E, Schüle B, Krainc D, Palmer TD, Wang X. Functional Impairment in Miro Degradation and Mitophagy Is a Shared Feature in Familial and Sporadic Parkinson's Disease. Cell Stem Cell. 2016; 19:709-24. https://doi.org/10.1016/j.stem.2016.08.002

28. Cai Q, Sheng ZH. Moving or stopping mitochondria: miro as a traffic cop by sensing calcium. Neuron. 2009; 61:49396. https://doi.org/10.1016/j.neuron.2009.02.003

29. Twig G, Liu X, Liesa M, Wikstrom JD, Molina AJ, Las G, Yaniv G, Hajnóczky G, Shirihai OS. Biophysical properties of mitochondrial fusion events in pancreatic beta-cells and cardiac cells unravel potential control mechanisms of its selectivity. Am J Physiol Cell Physiol. 2010; 299:C477-87. https://doi.org/10.1152/ajpcell.00427.2009

30. Wang X, Winter D, Ashrafi G, Schlehe J, Wong YL, Selkoe D, Rice S, Steen J, LaVoie MJ, Schwarz TL. PINK1 and Parkin target Miro for phosphorylation and degradation to arrest mitochondrial motility. Cell. 2011; 147:893-906. https://doi.org/10.1016/j.cell.2011.10.018

31. Hirosumi J, Tuncman G, Chang L, Görgün CZ, Uysal KT, Maeda K, Karin M, Hotamisligil GS. A central role for JNK in obesity and insulin resistance. Nature. 2002; 420:333-36. https://doi.org/10.1038/nature01137
32. Aguirre V, Uchida T, Yenush L, Davis R, White MF. The c-Jun $\mathrm{NH}(2)$-terminal kinase promotes insulin resistance during association with insulin receptor substrate-1 and phosphorylation of Ser(307). J Biol Chem. 2000; 275:904754. https://doi.org/10.1074/jbc.275.12.9047

33. Guo S, Dunn SL, White MF. The reciprocal stability of FOXO1 and IRS2 creates a regulatory circuit that controls insulin signaling. Mol Endocrinol. 2006; 20:3389-99. https://doi.org/10.1210/me.2006-0092

34. Dong XC, Copps KD, Guo S, Li Y, Kollipara R, DePinho RA, White MF. Inactivation of hepatic Foxo1 by insulin signaling is required for adaptive nutrient homeostasis and endocrine growth regulation. Cell Metab. 2008; 8:65-76. https://doi.org/10.1016/j.cmet.2008.06.006

35. Schon EA, Przedborski S. Mitochondria: the next (neurode) generation. Neuron. 2011; 70:1033-53. https://doi. org/10.1016/j.neuron.2011.06.003

36. Xing Y, Liqi Z, Jian L, Qinghua Y, Qian Y. Doxycycline Induces Mitophagy and Suppresses Production of Interferon- $\beta$ in IPEC-J2 Cells. Front Cell Infect Microbiol. 2017; 7:21. https://doi.org/10.3389/fcimb.2017.00021

37. Wurm T, Chen H, Hodgson T, Britton P, Brooks G, Hiscox JA. Localization to the nucleolus is a common feature of coronavirus nucleoproteins, and the protein may disrupt host cell division. J Virol. 2001; 75:9345-56. https://doi. org/10.1128/JVI.75.19.9345-9356.2001 